\title{
Regulation of lipid synthesis by liver $X$ receptor $\alpha$ and sterol regulatory element-binding protein 1 in mammary epithelial cells
}

\author{
C. Oppi-Williams, ${ }^{1}$ J. K. Suagee, ${ }^{1}$ and B. A. Corl ${ }^{2}$ \\ Department of Dairy Science, Virginia Tech, Blacksburg 24061
}

\begin{abstract}
The objectives of this experiment were to characterize the roles of the transcription factors liver X receptor $\alpha(\mathrm{LXR} \alpha)$ and sterol regulatory element-binding protein 1 (SREBP1) in the transcriptional regulation of lipid synthesis in a bovine mammary epithelial cell line. Whereas many lipid synthesis genes contain a response element in their promoters for SREBP1, a few also contain a response element for LXR, suggesting that both transcription factors could directly regulate transcription of these genes. However, the promoter of SREBP1 contains a response element for LXR, indicating the additional potential for indirect transcriptional regulation by LXR, through SREBP1, on lipogenic genes. To characterize these effects, small interfering RNA (siRNA) directed against LXR $\alpha$ and SREBP1 were used to knockdown gene expression, and then, in the presence of SREBP1 siRNA, T0901317 (T09) was used to specifically activate LXR $\alpha$. Reducing LXR $\alpha$ mRNA abundance in mammary alveolar $\mathrm{T}$ cells did not alter mRNA abundance of genes involved in de novo lipogenesis or the rate of de novo lipogenesis, suggesting that LXR $\alpha$ is not required for basal transcription of genes required for fatty acid synthesis. Knockdown of SREBP1 reduced the mRNA abundance of acetylcoenzyme A ( CoA) carboxylase, fatty acid synthase, diacylglycerol acyltransferase, and stearoyl-CoA desaturase-1, indicating that these genes are regulated in part by SREBP1. When SREBP1 was reduced, T09 increased the mRNA abundance of acetyl-CoA carboxylase, fatty acid synthase, and diacylglycerol acyltransferase, potentially indicating that these genes are directly regulated by LXR. The results of the present study provide insight into the transcriptional regulatory mechanisms involved in lipid synthesis by mammary epithelial cells, and suggest that several transcription factors may be required for full lipogenic activation.
\end{abstract}

Received December 19, 2011.

Accepted September 7, 2012.

${ }^{1}$ These authors contributed equally to this work.

${ }^{2}$ Corresponding author: bcorl@vt.edu
Key words: liver X receptor, small interfering RNA, sterol regulatory element-binding protein-1, transcriptional regulation

\section{INTRODUCTION}

Lipid synthesis involves the de novo synthesis of FA in addition to incorporation of de novo and preformed FA into triglycerides, processes that primarily occur in the liver, adipose, and mammary gland of mammals. Activation of these metabolic pathways requires the coordinated regulation of a network of genes encoding lipogenic enzymes, such as the de novo FA synthesis genes FA synthase $(\boldsymbol{F A} \boldsymbol{S N})$ and acetyl-CoA carboxylase $(\boldsymbol{A C C})$; the FA modification gene stearoyl-CoA desaturase-1 ( $\boldsymbol{S C D 1}$ ); and triglyceride synthesis genes, including glycerol phosphate acyltransferase $(\boldsymbol{G P A T})$, acylglycerol-3-phosphate O-acyltransferase $(\boldsymbol{A} \boldsymbol{G P A T})$, and diacylglycerol acyltransferase $(\boldsymbol{D G} \boldsymbol{A T})$. Two transcription factors considered critical for the activation of these genes are liver X receptors (LXR) and sterol regulatory element-binding protein 1 (SREBP1).

Liver $\mathrm{X}$ receptor $\alpha$ and its isoform LXR $\beta$ are nuclear receptors responsive to oxysterols or synthetic agonists, such as T0901317 (T09). Upon activation, LXR form heterodimers with the retinoid X receptor before binding to LXR response elements (LXRE) in the promoter of LXR-responsive genes. In mice, the specific knockout of LXR $\alpha$ reduces hepatic mRNA abundance of FASN and SCD1, but not $A C C$ (Peet et al., 1998), whereas in human preadipocytes, LXR $\alpha$ activation with T09 increases FASN, $A C C$, and SCD1 mRNA (Darimont et al., 2006). These findings suggest that LXR could have roles in lipogenic gene regulation, maintaining the expression of some genes and activating others.

In its precursor form, SREBP1 is a membrane-bound transcription factor located in the endoplasmic reticulum that is activated by proteolytic cleavage to its mature form (Wang et al., 1994). Mature SREBP1 translocates to the nucleus where it activates lipogenic genes by binding to the SREBP1 response element (SRE) of target genes, such as $A C C$ (Lopez et al., 1996), FASN (Magaña and Osborne, 1996), and GPAT (Ericsson et al., 1997). In chicken hepatocarcinoma cells, small 
interfering RNA (siRNA)-mediated knockdown of SREBP1 reduced $A C C$, but not FASN mRNA (Wang et al., 2009). Similar to LXR regulation of lipogenic genes, SREBP1 could be involved in both maintenance and activation of different genes. Additionally, the SREBP1 promoter contains an LXRE (Lengi and Corl, 2010), and SREBP1 mRNA is increased following T09 activation of LXR (Darimont et al., 2006; McFadden and Corl, 2010). Thus, many lipogenic genes can be directly activated by LXR $\alpha$ and SREBP1, and indirectly activated in the absence of an LXRE in the gene promoter by LXR $\alpha$ through SREBP1 activation.

In dairy cows, SREBP1 is considered a primary regulator of lipid synthesis in the mammary gland, as diets that induce milk fat depression also reduce SREBP1 expression (Harvatine and Bauman, 2006). Additionally, LXR $\alpha$ is considered a potentially important regulator of milk fat synthesis, as expression of LXR $\alpha$ is increased during the transition from pregnancy to lactation (Mani et al., 2009), and stimulation of bovine mammary epithelial cells with T09 increases de novo FA synthesis (McFadden and Corl, 2010). Therefore, the main objective of these experiments was to investigate the regulation of genes involved in milk fat synthesis by SREBP1 and LXR $\alpha$ in bovine mammary alveolar T (MAC-T) cells, to characterize the role of LXR $\alpha$ in mammary epithelial cell lipid synthesis.

\section{MATERIALS AND METHODS}

\section{Cell Culture and Transfection}

The MAC-T cells used in this study were routinely grown at $37^{\circ} \mathrm{C}$ and $5 \% \mathrm{CO}_{2}$ in growth media [Dulbecco's modified Eagle medium-high glucose (Sigma-Aldrich, St. Louis, MO) supplemented with $10 \%$ fetal bovine serum (Atlanta Biologicals Inc., Lawrenceville, GA), 10 $\mathrm{kU}$ of penicillin/mL, $10 \mathrm{mg}$ of streptomycin/mL, and $25 \mu \mathrm{g} / \mathrm{mL}$ of amphotericin (Sigma-Aldrich)]. For transfections, cells were seeded into 6 well plates at a density of $2 \times 10^{4}$ cells $/ \mathrm{cm}^{2}$ and incubated in growth media overnight. Cells were transfected with $100 \mathrm{n} M$ siRNA (Dharmacon, Thermo Fisher Scientific Inc., Waltham, $\mathrm{MA}$ ) and $4 \mu \mathrm{L}$ of transfection reagent (DharmaFECT transfection reagent no. 2; Thermo Scientific Inc.) in serum and antibiotic-free transfection media [Dulbecco's modified Eagle medium-high glucose supplemented with $0.1 \mu \mathrm{g}$ of insulin $/ \mathrm{mL}$ and $1.5 \mu \mathrm{g} / \mathrm{mL}$ of prolactin (Sigma-Aldrich)]. For the first experiment, treatments included specific anti-LXR $\alpha$ siRNA (LX; an equal mix of 3 sequences) and siRNA with a random sequence $(\mathbf{R N})$. For the second experiment, treatments consisted of anti-SREBP1 siRNA in transfection media (SR; an equal mix of 2 sequences) or transfection media supple-
Table 1. Sequences of small interfering RNA oligonucleotides

\begin{tabular}{ll}
\hline Target $^{1}$ & Sequence \\
\hline LXR $\alpha 1$ & GCUAAAUGAUGCUGAGUUUUU \\
LXR $\alpha 2$ & UGCAGGAGAUCGUGGAUUUUU \\
LXR $\alpha 3$ & GCUGAAGACGUCUGCGAUUUU \\
SREBP 11 & CCACAACGCCATCGAGAAA \\
SREBP 12 & GCACCGAGGCCAAGTTGAA \\
\hline
\end{tabular}

${ }^{1} \mathrm{LXR}=$ liver $\mathrm{X}$ receptor; $\mathrm{SREBP}=$ sterol regulatory element-binding protein.

mented with T09 [SRT; $2.5 \mu M$ T09 (Sigma-Aldrich)], the RN treatment, and the $\mathrm{RN}$ treatment in T09supplemented media (RNT). Sequences of the siRNA oligonucleotides are shown in Table 1. All experiments were repeated 3 to 4 times and cells were harvested at $48 \mathrm{~h}$ for gene and protein expression analysis, or for use in acetate incorporation assays.

\section{RNA Extraction and Real-Time Quantitative PCR}

Total RNA was extracted using RNAzol (Molecular Research Center Inc., Cincinnati, $\mathrm{OH}$ ) according to the manufacturer's instructions and quantified using a spectrophotometer (NanoDrop; Thermo Fisher Scientific Inc.). Adequate RNA purity was determined by samples having a $260 / 280$ ratio greater than 1.80 , and following this, RNA was reverse transcribed to cDNA (1 $\mu \mathrm{g}$ per $20-\mu \mathrm{L}$ reaction; Omniscript RT kit; Qiagen Inc., Valencia, CA). Quantification of transcripts was performed using SYBR Green master mix (GoTaq qPCR kit; Promega Corp., Madison, WI) and $0.25 \mu M$ gene-specific primers (Table 2 ) in a $25-\mu \mathrm{L}$ reaction containing $125 \mathrm{ng}$ of cDNA. Reactions were incubated in a thermocycler (7300 real-time PCR machine; Applied Biosystems Inc., Foster City, CA) at $95^{\circ} \mathrm{C}$ for $15 \mathrm{~min}$, followed by 35 cycles of $95^{\circ} \mathrm{C}(30 \mathrm{~s}), 60.5^{\circ} \mathrm{C}(15 \mathrm{~s})$, and $72^{\circ} \mathrm{C}(1 \mathrm{~min})$. Each reaction was performed in duplicate wells. $\beta$-Actin was used as the endogenous control gene and cycle threshold $\left(\mathbf{C}_{\mathbf{t}}\right)$ values were not influenced by treatments. Melt curves were analyzed for all reactions. Fold change was calculated using $2^{-\Delta \Delta \mathrm{Ct}}$ method (Livak and Schmittgen, 2001) with the RN treatment as the calibrator.

Gene-specific primers for the transcripts used in the study are shown in Table 2. Primer pair specificity was validated by sequencing products generated from PCR reactions. Primer pair efficiencies were calculated by generating a standard curve with 5 -fold serial dilutions of cDNA for each primer pair. Each reaction was performed in triplicate. The slope of the curve was calculated for each primer pair, and efficiency was calculated as efficiency $=10^{(-1 / \text { slope })}$, with an efficiency of 2 (indicating exact doubling for each cycle) equaling 
Table 2. Sequences of primers used for real-time PCR amplification

\begin{tabular}{lllr}
\hline Identification $^{1}$ & Forward primer & Reverse primer & $\begin{array}{c}\text { Efficiency of } \\
\text { primer pair, } \%\end{array}$ \\
\hline LXR $\alpha$ & GACCGACTGATGTTCCCAAG & ACAGAAGACACGGAGGAGGA & 95.1 \\
LXR $\beta$ & TGTTGTCTTACACCCGCATC & CAGTCCCTTCCTACCCCAGT & 104.5 \\
SREBP 1 & ATGCCATCGAGAAACGCTAC & GTCCGCAGACTCAGGTTCTC & 100.0 \\
$A B C G 1$ & GACTCGGTCCTCACGCAC & CGGAGAAACACGTCCATCTC & 99.4 \\
$F A S N$ & AACACCATGTGGCAGGAAGT & TGTAGCCGTTTCACCAGTAA & 99.6 \\
$A C C 1$ & GGGTGAAAGACTGGGTTGAA & GACAGAGCACGGATGTGATG & 100.5 \\
$A G P A T$ & AAGCAAGTTGCCATCCTCA & AAACTGTGGCTCCAATTCGA & 96.6 \\
$D G A T$ & GACACAGACAAGGACGGAGA & CAGCATCACCACACACCAA & 103.8 \\
$G P A T$ & ATTGACCCTTGGCACGATAG & AACAGCACCTTCCCACAAAG & \\
LPL & GAGCCAAAAGAAGCAGCAAG & AGGCAGGGTAAAGGGATGT & 99.3 \\
SCD1 & CCCTTTCCTTGAGCTGTCTG & ATGCTGACTCTCTCCCCTGA & \\
Actin & CTCTTCCAGCCTTCCTTCCT & GGGCAGTGATCTCTTTCTGC & 98.2 \\
\hline
\end{tabular}

${ }^{1} \mathrm{LXR}=$ liver $\mathrm{X}$ receptor; SREBP $=$ sterol regulatory element-binding protein; $A B C G=\mathrm{ATP}$-binding cassette protein $\mathrm{G} ; F A S N=\mathrm{FA}$ synthase; $A C C=$ acetyl-CoA carboxylase; $A G P A T=$ acylglycerol-3-phosphate O-acyltransferase; $D G A T=$ diacylglycerol acyltransferase; $G P A T=$ glycerol phosphate acyltransferase; $L P L=$ lipoprotein lipase; $S C D=$ stearoyl CoA desaturase.

$100 \%$ efficiency. Primer pair efficiencies were between 95 and $105 \%$ for each primer pair (Table 2).

\section{Immunoblotting}

Western blot analysis of total ACC1 (rabbit antihuman ACC polyclonal antibody, 3662; Cell Signaling Technology Inc., Danvers, MA), SCD1 (custom synthesized rabbit anti-bovine antibody; Pacific Immunology Corp., Ramona, CA), FAS (rabbit anti-human FAS monoclonal antibody, 3180; Cell Signaling Technology Inc.), and SREBP1 (mouse anti-human SREBP1 monoclonal antibody SC-13551; Santa Cruz Biotechnology Inc., Santa Cruz, CA) was performed. The authors were unable to validate an antibody against bovine LXR $\alpha$. Media were removed and cells washed once with Dulbecco's modified PBS (DPBS; $5.36 \mathrm{mM} \mathrm{KCl,} 2.94 \mathrm{~m} M$ $\mathrm{KH}_{2} \mathrm{PO}_{4}, 273.78 \mathrm{mM} \mathrm{NaCl}$, and $16.2 \mathrm{mM} \mathrm{Na}_{2} \mathrm{HPO}_{4} ; \mathrm{pH}$ 7.4) before harvesting protein in $50 \mu \mathrm{L}$ of lysis buffer [50 m $M$ Tris-HCl, pH 7.4; 0.5\% (vol/vol) Triton X-100; $300 \mathrm{mM} \mathrm{NaCl} ; 2 \mathrm{~m} M$ EDTA, $\mathrm{pH} 8.0$; and $2 \%$ (vol/ vol) protease inhibitor cocktail (Sigma-Aldrich)]. Cells were incubated on ice for $10 \mathrm{~min}$, centrifuged at 16,000 $\times g$ for $15 \min \left(4^{\circ} \mathrm{C}\right)$, and the resulting supernatant retained. Protein concentrations were quantified by the Bradford assay (Quick Start Bradford protein assay; Bio-Rad Laboratories Inc., Hercules, CA), adjusted to $2 \mu \mathrm{g} / \mu \mathrm{L}$ by addition of cold lysis buffer, combined with an equivalent volume of $2 \times$ Laemmli sample buffer (Sigma-Aldrich), and boiled at $95^{\circ} \mathrm{C}$ for $10 \mathrm{~min}$.

For ACC1, $45 \mu \mathrm{g}$ of protein per sample was resolved on a $7.5 \%$ SDS-polyacrylamide gel (Lonza PAGEr Gold Plus Precast Gels; Lonza Rockland Inc., Rockland, $\mathrm{ME}$ ); for SCD1, $30 \mu \mathrm{g}$ of protein was resolved on a $12 \%$ gel; for FAS, $30 \mu \mathrm{g}$ of protein was resolved on a $7.5 \%$ gel; and for SREBP1, $40 \mu \mathrm{g}$ of protein was resolved on a $12 \%$ SDS gel before transfer to a polyvinylidene difluoride (PVDF) membrane (Amersham Hybond-P; GE Healthcare UK Ltd., Buckinghamshire, UK). Membranes were blocked with Tris-buffered saline (TBS) that included $0.1 \%$ Tween-20 and 5\% dried nonfat milk (ACC1, SCD1, and SREBP1) or TBS with $2 \%$ BSA (FAS) for $1 \mathrm{~h}$ at room temperature. Membranes were then incubated overnight with primary antibody (ACC1, 1:1000; SCD1, 1:1000; SREBP1, 1:1000; and FAS, 1:2000), followed by incubation with an appropriate secondary antibody (Santa Cruz Biotechnology Inc.) for $1 \mathrm{~h}$, and protein bands visualized with a chemiluminescent detection system (ECL Plus Western Blotting Detection System; GE Healthcare UK Ltd.). Following SCD1 visualization, membranes were stripped and probed with an antibody directed against $\beta$-actin (Sigma-Aldrich; monoclonal rabbit anti-mouse $\beta$-actin; 1:4000). For all antibodies, bands were visualized and quantified using a ChemiDoc XRS digital imaging system (Bio-Rad Laboratories Inc.).

\section{Acetate Incorporation Assay}

Following transfection, half of the media from each well was removed and replaced with media containing sodium acetate $(300 \mathrm{mM})$ and $\left[{ }^{14} \mathrm{C}\right]$ acetic acid $(37,000$ $\mathrm{Bq} /$ well; American Radiolabeled Chemicals Inc., St. Louis, MO). Following incubation $\left(4 \mathrm{~h}, 37^{\circ} \mathrm{C}, 5 \% \mathrm{CO}_{2}\right)$, media were removed and cells rinsed with a balanced salt solution before lysis with $0.1 \%$ SDS in DPBS. Lipids were extracted from the lysate with 3:2 hexane isopropanol, and total radioactivity in the organic phase quantified by liquid scintillation counting.

\section{Statistical Analysis}

The mixed models procedure of SAS (SAS Enterprise Guide v.4.2; SAS Institute Inc., Cary, NC) was used 
for all analyses. For all transcript abundance data, $2^{-\Delta \Delta \mathrm{Ct}}$ values were analyzed. The effect of LXR $\alpha$ siRNA on transcript abundance and acetate incorporation in MAC-T cells was assessed using a mixed model ANOVA for the main effect of treatment (RN or LX).

The effect of SREBP1 siRNA on transcript abundance, protein expression, and acetate incorporation in MAC-T cells was assessed using a mixed model ANOVA for the main effects of treatment (RN or SR) and T09 and the treatment by T09 interaction. Where a significant treatment by T09 interaction was detected, means were separated using the Tukey procedure. Densitometry data for FASN were log transformed to improve normality of residuals.

\section{RESULTS}

Treatment of MAC-T cells with LXR $\alpha$ siRNA reduced $\operatorname{LXR} \alpha(P<0.001)$ and $\operatorname{LXR} \beta(P<0.001)$ mRNA abundance by 80 and $50 \%$ (Figure 1), respectively, while not altering acetate incorporation $(P>0.3$; Figure 1). Knockdown of LXR $\alpha$ did not alter $A B C G 1$ mRNA abundance $(P>0.4)$, however it did increase $L P L(P=0.002), S C D 1(P=0.001)$, and SREBP1 $(P=0.017)$ mRNA abundance (Table 3$)$. Neither the de novo FA synthesis genes $A C C 1$ and $F A S N$, nor the triglyceride synthesis genes AGPAT, GPAT, and DGAT were altered by reduced LXR $\alpha(P>0.2$; Table 3$)$.

A treatment by T09 interaction existed for mRNA abundance of SREBP1 $(P<0.001$; Figure 2), whereby SREBP1 siRNA decreased SREBP1 mRNA in both SR- and SRT-treated cells $(P<0.001)$ and T09 increased SREBP1 mRNA in RN-treated cells only ( $P$

Table 3. Mean abundance of transcripts in mammary alveolar $\mathrm{T}$ cells (MAC-T) transfected with nontargeting small interfering RNA $($ siRNA; RN) or liver $\mathrm{X}$ receptor $\alpha(\mathrm{LXR} \alpha)$ siRNA $(\mathrm{LX} ; \mathrm{n}=5)$

\begin{tabular}{lcccc}
\hline & \multicolumn{2}{c}{ Treatment } & & \\
\cline { 2 - 3 } Transcript $^{1}$ & $\mathrm{RN}$ & $\mathrm{LX}$ & SEM $^{2}$ & $P$-value \\
\hline ABCG1 & 1.00 & 1.12 & 0.10 & 0.43 \\
SREBP1 & 1.00 & 1.41 & 0.09 & 0.017 \\
LPL & 1.02 & 2.24 & 0.19 & 0.002 \\
ACC1 & 1.01 & 0.86 & 0.07 & 0.20 \\
FASN & 1.00 & 0.88 & 0.07 & 0.29 \\
GPAT & 1.00 & 0.89 & 0.10 & 0.44 \\
AGPAT & 1.02 & 0.86 & 0.09 & 0.26 \\
DGAT & 1.00 & 1.06 & 0.05 & 0.40 \\
SCD1 & 1.00 & 1.30 & 0.04 & 0.001 \\
\hline
\end{tabular}

${ }^{1} \mathrm{ABCG}=$ ATP-binding cassette protein $\mathrm{G}$; SREBP $=$ sterol regulatory element-binding protein $\mathrm{G}$; $\mathrm{LPL}=$ lipoprotein lipase; $\mathrm{ACC}=$ acetyl-CoA carboxylase; FASN $=$ FA synthase; AGPAT $=$ acylglycerol-3-phosphate O-acyltransferase; GPAT = glycerol phosphate acyltransferase; DGAT = diacylglycerol acyltransferase; SCD = stearoylCoA desaturase.

${ }^{2}$ Pooled SEM.
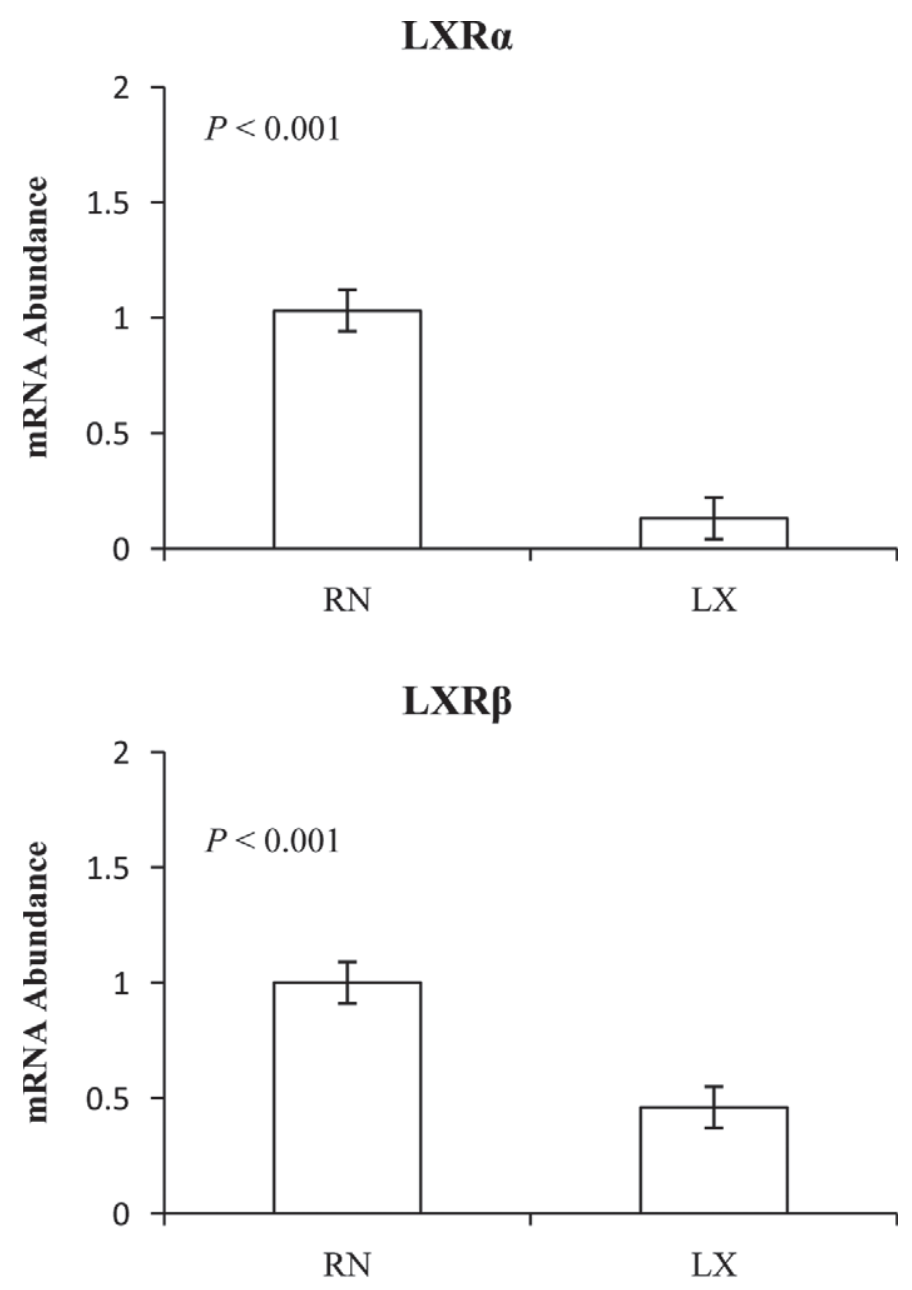

Acetate incorporation

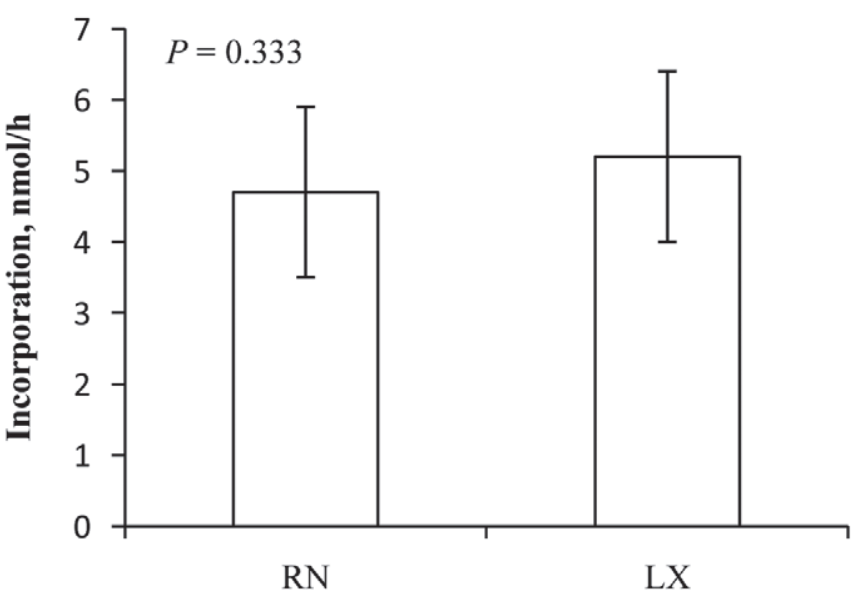

Treatment

Figure 1. Transcript fold change of liver X receptor $\alpha(\operatorname{LXR} \alpha)$ and LXR $\beta$ and $\left[{ }^{14} \mathrm{C}\right]$-labeled acetate incorporation into mammary alveolar $\mathrm{T}$ (MAC-T) cells transfected with nontargeting small interfering RNA ( iRNA; RN) or LXR $\alpha$ siRNA (LX; $\mathrm{n}=4)$. Data are presented as means \pm pooled SEM. 
$<0.001)$. For SREBP1 protein levels, a main effect of treatment was observed, whereby SREBP1 siRNA reduced mature SREBP1 protein abundance $(P<0.001$; Figure 2) with no effect of T09 $(P>0.1)$ in either RN- or SR-treated cells $(P>0.1)$. Acetate incorporation was reduced by SREBP1 knockdown $(P<0.001$; Figure 2), but was increased by T09 in both SR- and RN-treated $(P<0.001)$ cells.

A treatment by T09 interaction existed for abundance of $A B C G 1$ mRNA $(P=0.012)$, whereby the SR treat- ment did not influence $A B C G 1 \mathrm{mRNA}$ in the absence of T09 $(P>0.5)$ but in the presence of T09, was lower in SR-treated than $\mathrm{RN}$-treated cells $(P=0.055$; Table 4). Knockdown of SREBP1 reduced mRNA abundance of the de novo lipogenesis genes, $A C C 1(P<0.001$; Figure 3) and FASN $(P<0.001$; Figure 4$)$, while having no effect on $L P L(P>0.1$; Table 4$)$. Protein abundance of $\operatorname{ACC} 1(P=0.049 ;$ Figure 3$)$ and FASN $(P=0.007$; Figure 4) were decreased by SREBP1 knockdown. Inclusion of T09 in culture media increased $A C C 1$ (Figure
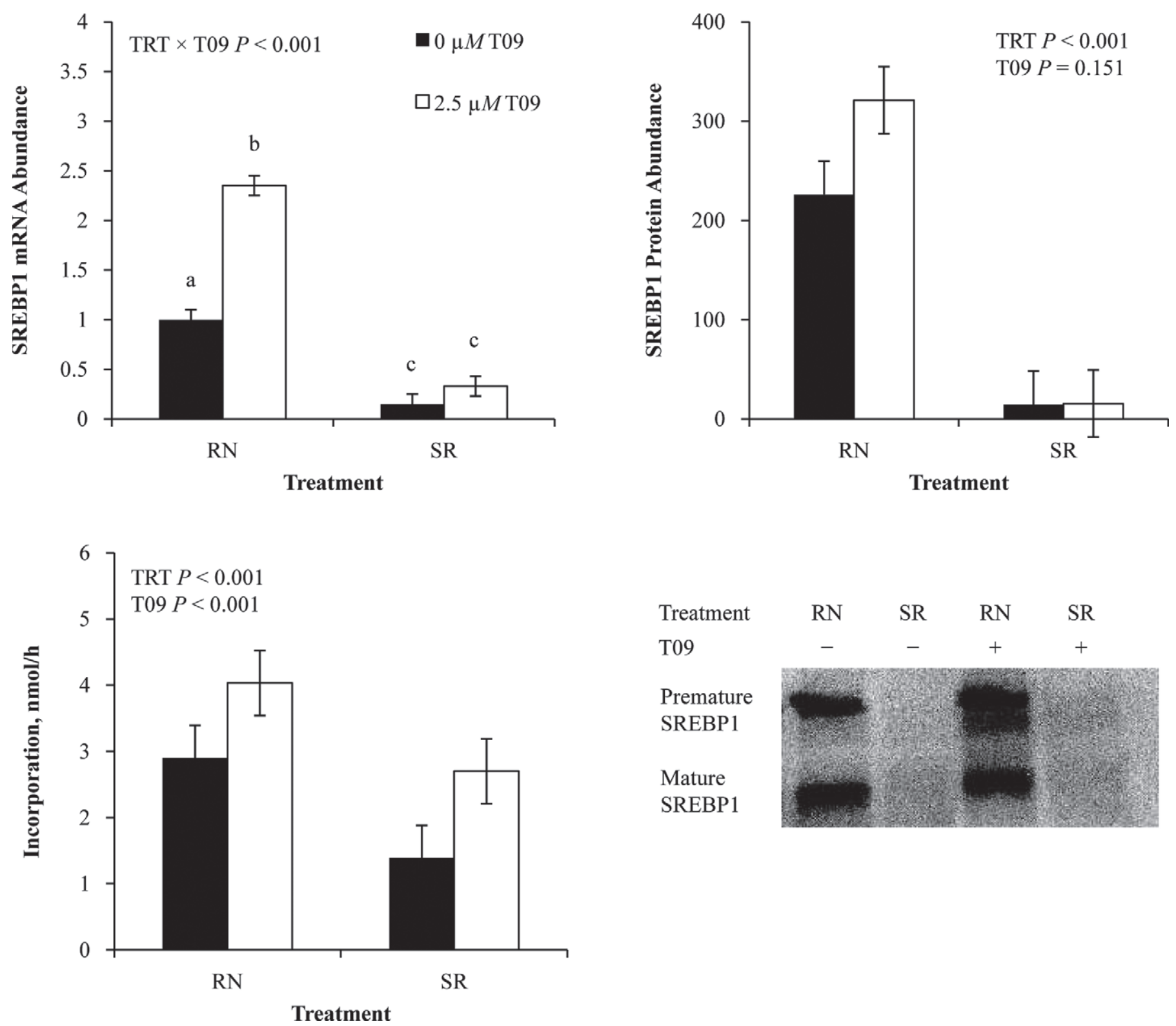

Figure 2. Transcript fold change (top left panel) and protein (top right panel) abundance of sterol regulatory element-binding protein 1 (SREBP1), and $\left[{ }^{14} \mathrm{C}\right]$-labeled acetate incorporation (lower left panel) in mammary alveolar $\mathrm{T}$ (MAC-T) cells transfected with nontargeting small interfering RNA (siRNA; RN) or SREBP1 siRNA (SR; $\mathrm{n}=4$ ). Cell culture media included either 0 or $2.5 \mu M$ synthetic agonist T0901317 (T09). Data are presented as means \pm pooled SEM. Different letters $(\mathrm{a}-\mathrm{c})$ indicate differences $(P<0.001)$. TRT $=$ treatment. 
Table 4. Mean abundance ( \pm SEM) of transcripts in mammary alveolar T (MAC-T) cells transfected with nontargeting small interfering RNA (siRNA; RN) or sterol regulatory element-binding protein 1 (SREBP1) siRNA (SR), in media that included either 0 or $2.5 \mu M$ synthetic agonist T0901317 (T09; RNT or SRT; $\mathrm{n}=4$ )

\begin{tabular}{|c|c|c|c|c|c|c|c|}
\hline Transcript $^{1}$ & \multicolumn{4}{|c|}{ Treatment $^{2}$} & \multicolumn{3}{|c|}{$P$-value } \\
\hline ABCG1 & $1.00 \pm 0.26^{\mathrm{a}}$ & $1.45 \pm 0.26^{\mathrm{a}}$ & $6.21 \pm 0.26^{\mathrm{b}}$ & $5.09 \pm 0.30^{\mathrm{c}}$ & 0.20 & $<0.001$ & 0.012 \\
\hline LXR $\beta$ & $1.00 \pm 0.08$ & $1.50 \pm 0.08$ & $0.91 \pm 0.08$ & $1.34 \pm 0.10$ & $<0.001$ & 0.16 & 0.70 \\
\hline LPL & $1.00 \pm 0.08$ & $1.27 \pm 0.08$ & $1.30 \pm 0.08$ & $1.38 \pm 0.08$ & 0.11 & 0.078 & 0.32 \\
\hline GPAT & $1.00 \pm 0.15$ & $0.99 \pm 0.15$ & $1.32 \pm 0.15$ & $1.13 \pm 0.18$ & 0.53 & 0.18 & 0.56 \\
\hline
\end{tabular}

${ }^{\mathrm{a}-c}$ Unlike superscripts within a row indicate that means are different, $P<0.05$.

${ }^{1} \mathrm{ABCG}=$ ATP-binding cassette protein G; LXR = liver X receptor; LPL = lipoprotein lipase; AGPAT = acylglycerol-3-phosphate O-acyltransferase; GPAT = glycerol phosphate acyltransferase; DGAT = diacylglycerol acyltransferase.

${ }^{2} \mathrm{RN}=$ nontargeting; $\mathrm{SR}=\mathrm{SREBP1}$ siRNA; RNT = RN treatment in T09-supplemented media; SRT = SR media supplemented with T09.

${ }^{3}$ For SRT treatment, $\mathrm{n}=3$ for ABCG1, LXR $\beta$, GPAT, and DGAT.

${ }^{4} \mathrm{TRT}=$ treatment.

3) and FASN (Figure 4) mRNA in both SREBP1 siRNA-treated and RN-treated cells $(P<0.001)$, whereas neither ACC1 $(P>0.2$; Figure 3$)$ nor FASN $(P>0.08$; Figure 4) protein abundance was influenced by T09.

Knockdown of SREBP1 increased mRNA abundance of the triglyceride synthesis gene DGAT $(P=0.005)$, while having no effect on GPAT $(P>0.5)$ or AGPAT $(P>0.07$; Table 4$)$. Inclusion of T09 in culture medium had no effect on GPAT $(P>0.1)$ or AGPAT $(P>$ 0.3 ) but increased $D G A T$ mRNA in cells treated with SREBP1 and nontargeting siRNA $(P=0.023$; Table $4)$. The mRNA $(P<0.001 ;$ Figure 5$)$ and protein $(P<$ 0.001; Figure 5) abundance of SCD1 were decreased by SREBP1 knockdown, and neither mRNA nor protein was influenced in either treatment by addition of T09 to culture medium $(P>0.1)$. Abundance of $L X R \alpha$ was not influenced by either SREBP1 knockdown $(P>0.2)$ or T09 $(P>0.8)$, whereas $L X R \beta$ mRNA was increased by SREBP1 knockdown $(P<0.001)$ but was not altered by T09 $(P>0.1$; Table 4$)$.

\section{DISCUSSION}

Mammary gland fat synthesis occurs in mammary epithelial cells, with lipids being secreted as membranebound fat globules. The transcription factor SREBP1 is considered a global regulator of lipid metabolism, and inhibiting SREBP1 activation reduces lipogenesis and lipogenic gene expression in the liver of mice (Kuriyama et al., 2005). Transcription of SREBP1 is stimulated by insulin (Foufelle and Ferre, 2002) and this stimulation is potentially mediated, in part, by LXR $\alpha$ (Fiévet and Staels, 2009), as disruption of the LXRE site in the SREBP1 promoter does not reduce basal transcription, but does prevent insulin-stimulated SREBP1 expres- sion (Chen et al., 2004). Both SREBP1 and LXR $\alpha$ are considered important regulators of lipogenic gene expression in dairy cows and the mRNA abundance of both are increased with the onset of lactation (Mani et al., 2009). Further, it is now known that the bovine SREBP1 promoter contains LXRE sites that are critical for T09-stimulated activation (Lengi and Corl, 2010).

The LXR $\alpha$ nuclear receptor was initially identified as being responsible for increasing lipogenic gene expression in response to the presence of oxidized cholesterol derivatives. These derivatives bind LXR $\alpha$ and activate it, through conformational changes, to dimerize with the retinoid-X receptor and then bind to LXRE in the promoter region of target genes. Although it is likely that the primary method by which LXR $\alpha$ increases lipogenic genes is through SREBP1 (Repa et al., 2000; Schultz et al., 2000), the promoter of some lipogenic genes, including FASN, contain an LXRE (Joseph et al., 2002), potentially indicating that LXR $\alpha$ is as influential as SREBP1 in stimulating lipogenic genes. Thus, the primary objective of these experiments was to determine the relative importance of LXR $\alpha$ and SREBP1 on lipogenic gene expression and de novo FA synthesis in MAC-T cells.

Reducing $L X R \alpha$ mRNA abundance in MAC-T cells resulted in the primary finding that both the abundance of transcripts for proteins involved in de novo lipogenesis and the rate of de novo lipogenesis, as indicated by acetate incorporation, were unaltered. The de novo lipogenesis genes $A C C 1$ and FASN are under the control of both LXR $\alpha$ and SREBP1 (Lopez et al., 1996; Magaña and Osborne, 1996; McFadden and Corl, 2010), with previous work in bovine mammary epithelial cells demonstrating that T09 activation strongly increases their gene expression (McFadden and Corl, 

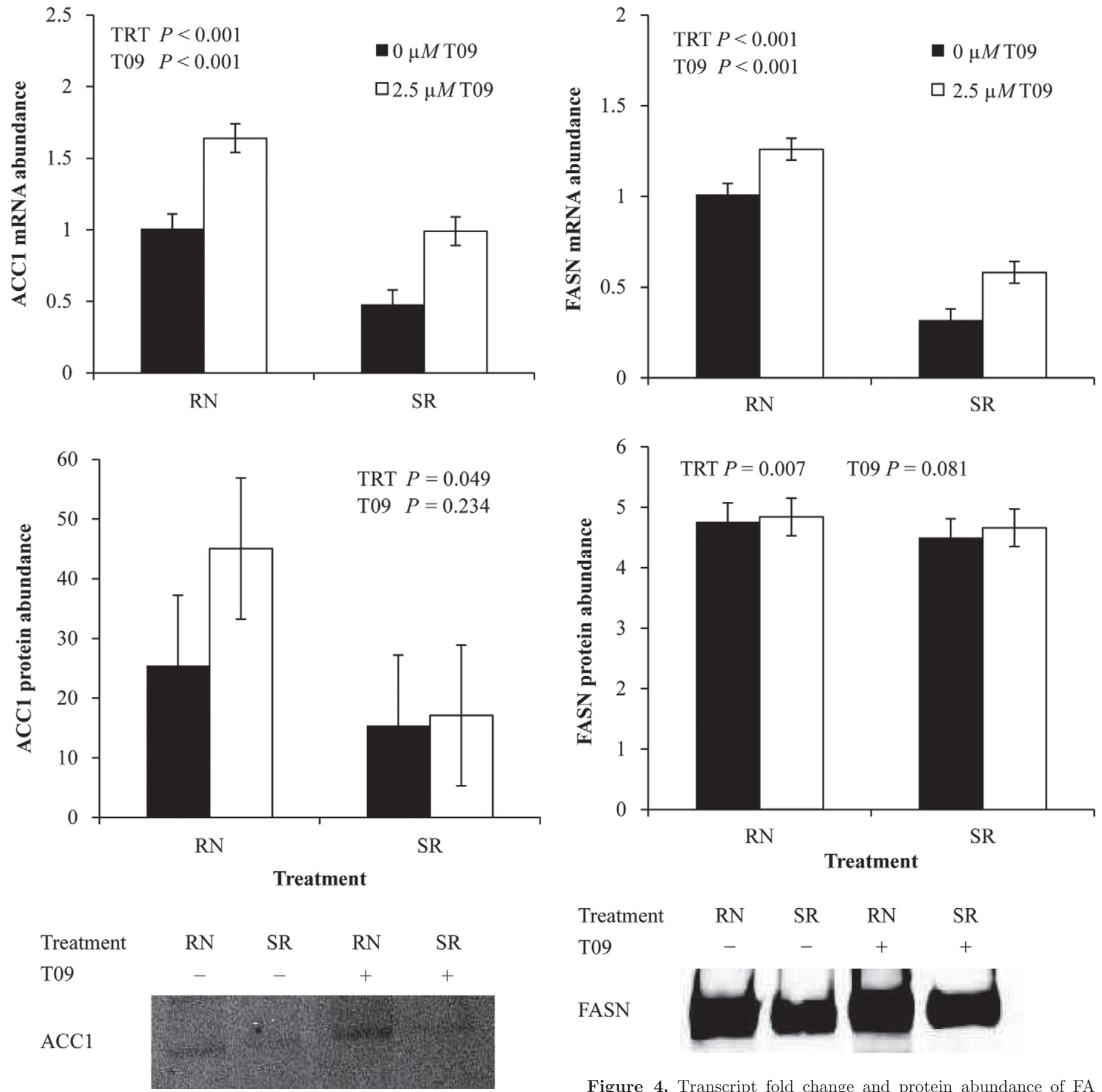

Figure 3. Transcript fold change and protein abundance of acetylCoA carboxylase 1 (ACC1) in mammary alveolar T (MAC-T) cells transfected with nontargeting small interfering RNA (siRNA; RN) or sterol regulatory element-binding protein 1 (SREBP1) siRNA (SR; n $=4$ ). Cell culture media included either 0 or $2.5 \mu \mathrm{M}$ synthetic agonist T0901317 (T09). Data are presented as means \pm pooled SEM. TRT $=$ treatment.

2010). We found that $A C C 1$ and $F A S N$ were unaltered by $\mathrm{LXR} \alpha$ reduction, which likely indicates that basal gene expression is maintained by other transcription

Figure 4. Transcript fold change and protein abundance of FA synthase (FASN) in mammary alveolar T (MAC-T) cells transfected with nontargeting small interfering RNA (siRNA; RN) or sterol regulatory element-binding protein 1 (SREBP1) siRNA (SR; $\mathrm{n}=4)$. Cell culture media included either 0 or $2.5 \mu M$ synthetic agonist T0901317 (T09). Data are presented as means \pm SEM (mRNA) or geometric mean \pm pooled SEM (protein). TRT $=$ treatment

factors, such as SREBP1, which was increased in response to LXR $\alpha$ knockdown. Alternatively, it is possible that LXR $\beta$, which was only reduced by $50 \%$ in the LX-treated cells, maintained lipogenic gene expression 

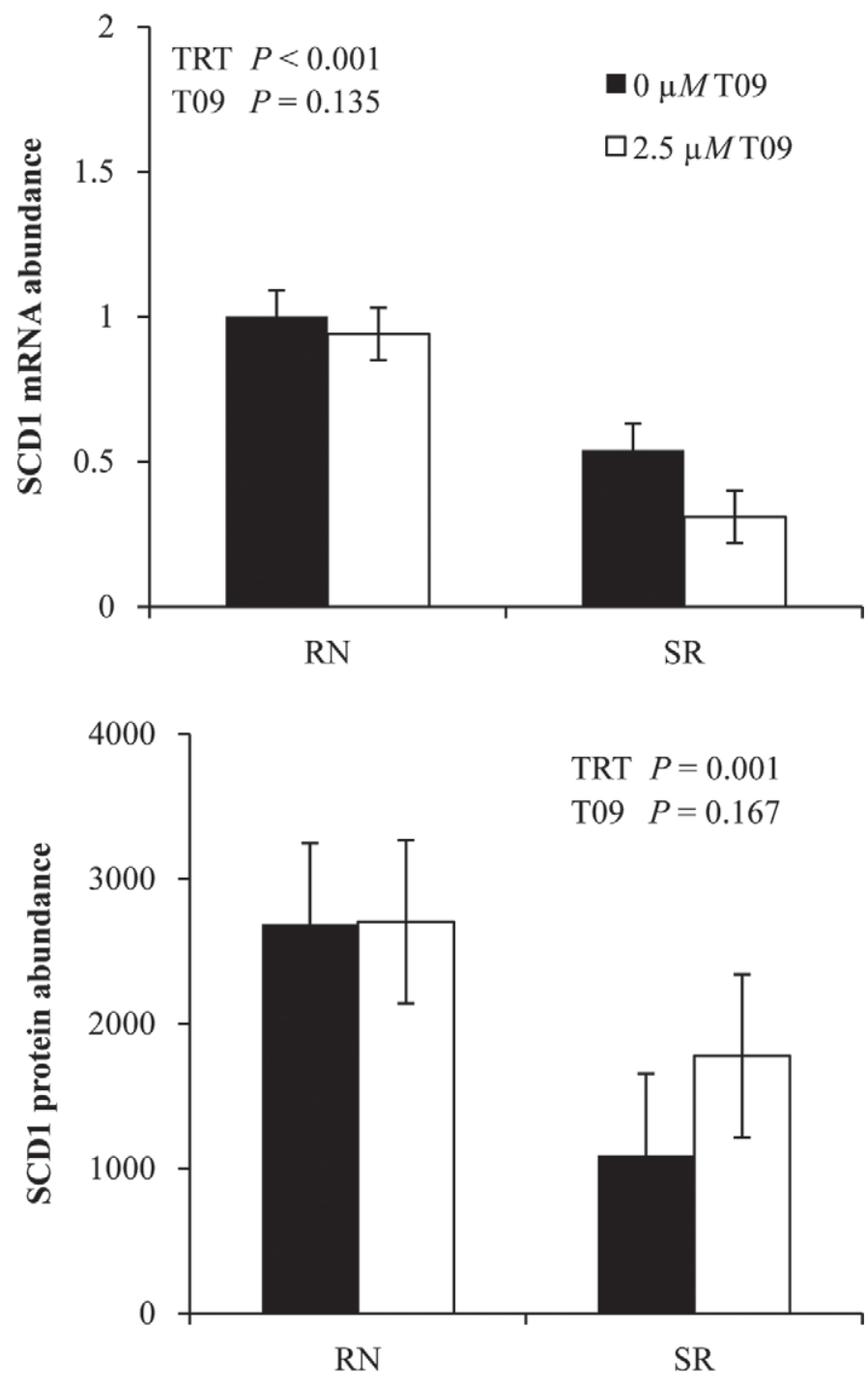

Treatment

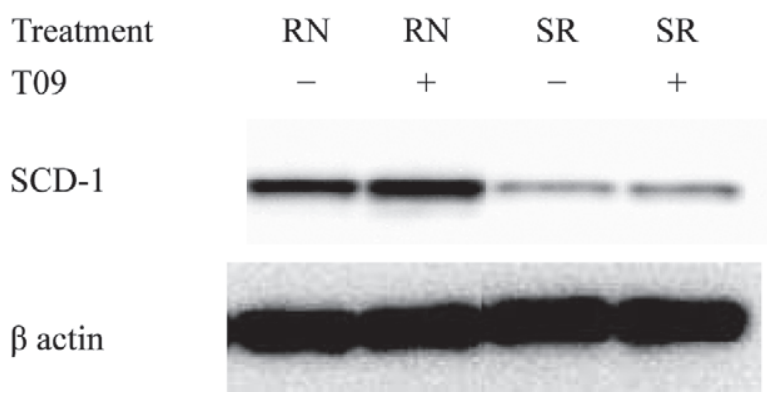

Figure 5. Transcript fold change of stearoyl-CoA desaturase 1 (SCD1) in mammary alveolar T (MAC-T) cells transfected with nontargeting small interfering RNA (siRNA; RN) or sterol regulatory element-binding protein 1 (SREBP1) siRNA (SR; $n=4)$. Cell culture media included either 0 or $2.5 \mu M$ synthetic agonist T0901317 (T09). Data are presented as means \pm pooled SEM. TRT $=$ treatment. with reduced abundance of LXR $\alpha$. The reduction of LXR $\beta$ is potentially due to sequence similarity between the 2 isoforms. Both $\alpha$ and $\beta$ isoforms dimerize with retinoid X receptor (RXR) and bind LXRE (Baranowski, 2008), indicating that complete knockdown of both may be required to determine the full effect of LXR on fat metabolism in MAC-T cells.

In opposition to the lack of change in transcripts for proteins involved in de novo lipogenesis, we observed increased SREBP1, LPL, and SCD1 mRNA in cells with reduced abundance of LXR $\alpha$. As the bovine SREBP1 promoter contains an SRE in addition to 2 LXRE (Lengi and Corl, 2010), it is possible that positive feedback signaling by SREBP1 itself contributed to increased SREBP1 mRNA abundance. The increase in SREBP1 might have then stimulated $L P L$ and SCD1 gene expression, increasing the abundance of these genes independent of LXR $\alpha$ activation. As shown in rodent species, gene expression of $L P L$ is primarily regulated by SREBP1 (Schoonjans et al., 2000), and previous work in bovine mammary epithelial cells shows regulation of SCD1 by SREBP1 (Ma and Corl, 2012).

Activation of LXR by T09 increased SREBP1 mRNA and mature protein by 135 and $42 \%$, respectively, a finding that supports previous work demonstrating the presence of an LXRE in the SREBP1 promoter (Lengi and Corl, 2010). This increase was paralleled by increased mRNA abundance of $A B C G 1, A C C 1$, and $F A S N$ by 521,64 , and $26 \%$, respectively. As $A B C G 1$ contains an LXRE but not an SRE, this increase is likely due to direct transcriptional activation by LXR (Sabol et al., 2005). In opposition to this, $A C C 1$ is highly responsive to SREBP1 stimulation, selectively responsive to LXR $\alpha$ at the PII promoter only, and unresponsive to LXR $\beta$ at all promoters (Zhao et al., 2010). As it is likely that all 3 promoters are relevant to $A C C 1$ transcription in mammary epithelial cells of dairy cows (Molenaar et al., 2003), it is possible that LXR $\alpha$ activated $A C C 1$ transcription directly through the PII promoter or indirectly through SREBP1. Similarly, the FASN promoter contains both LXRE and SRE sites, and gene expression is acutely stimulated by both T09 (McFadden and Corl, 2010) and insulin (Barthel et al., 2002). Similar to our ACC1 mRNA findings, the observed increase in FASN mRNA due to T09 stimulation could have been due to either direct LXR activation by T09 or the increase in mature SREBP1 protein levels. Intriguingly, the increases in FASN and ACC1 did not translate to increased protein levels. Lastly, T09 increased de novo lipogenesis, a finding in agreement with previous studies (McFadden and Corl, 2010).

With SREBP1 knockdown, SREBP1 mRNA was reduced by $85 \%$ and addition of T09 to the treatment media reduced this knockdown to $67 \%$. The effect of 
T09 on mRNA did not translate to an effect on mature protein levels, however, and mature SREBP1 remained undetectable in both SR- and SRT-treated cells. This indicates that any effects of T09 on other genes in cells treated with SREBP1 siRNA are likely due to LXR $\alpha$ directly binding the promoter and not to SREBP1. Further, although $L X R \alpha$ mRNA was not altered in response to SREBP1 knockdown, $L X R \beta$ mRNA was increased, regardless of T09, by an average of $42 \%$. It is, therefore, possible that LXR $\beta$ played a role in any mRNA increases due to SR or SRT treatment. The increase in the $L X R \beta$ isoform mRNA could be due to feedback signaling or a compensatory response to maintain lipogenic gene expression.

De novo lipogenesis was decreased in SREBP1 siRNA-treated cells, but, interestingly, was recovered with LXR activation. Similarly, both $A C C 1$ and FASN mRNA were reduced by SREBP1 knockdown and increased by T09 addition, suggesting that both transcription factors are significant regulators of lipogenesis, with SREBP1 necessary for maintaining basal levels and LXR capable of stimulation. However, T09 was unable to increase protein levels of FAS and ACC1 in cells with reduced SREBP1; thus, the mechanism of increased acetate incorporation is unknown.

Following elongation, long-chain FA are desaturated by SCD1 before triglyceride synthesis. Our finding that $S C D 1$ mRNA was reduced by SREBP1 knockdown is in agreement with previous studies in MAC-T cells (Ma and Corl, 2012) and suggests that SREBP1 is responsible for activating $S C D 1$ transcription in bovine cells. Data from other species suggests that $S C D 1$ is regulated by both SREBP1 and LXR, with $S C D 1$ being responsive to LXR activation by T09 in mouse liver (Weiss et al., 2011) and also increased by treatment that elevates SREBP1 mRNA levels (Yin et al., 2007). Our results from both the LXR $\alpha$ and SREBP1 knockdown experiments indicate that SREBP1 has primary regulatory responsibility for $S C D 1$ transcriptional regulation.

The final step of lipogenesis, triglyceride production, is facilitated by the enzymes GPAT, AGPAT, and DGAT, which attach long-chain FA in a successive manner to glycerol. In the present experiment, GPAT mRNA levels were not altered by either SREBP1 siRNA or T09. This disagrees with previous work demonstrating that SREBP1 siRNA reduced GPAT mRNA by approximately $20 \%$ (Ma and Corl, 2012), which suggested that SREBP1 is important in GPAT regulation. As T09 treatment had no effect on GPAT mRNA, it is unlikely that LXR is involved in transcriptional regulation of GPAT. Similarly, T09 did not influence AGPAT mRNA in RN-treated cells, suggesting that LXR is not involved in the transcriptional regulation of this gene. However, T09 did decrease DGAT mRNA abundance.
Knockdown of SREBP1 increased mRNA levels of both $A G P A T$ and DGAT, a finding that is in agreement with previous research (Ma and Corl, 2012). As the $L X R \beta$ isoform mRNA was also increased by SREBP1 knockdown, it is possible that $\operatorname{LXR} \beta$ could play a role in mediating these changes, depending on its activation.

Although much is known about how dietary factors affect milk fat production, little is known about the transcriptional programs that mediate these effects. For instance, supplementation of diets with fish or plant oils results in milk fat depression, and this correlates with lower mRNA abundance of ACC1, FASN, GPAT, and AGPAT (Peterson et al., 2003). It is known that biohydrogenation of PUFA in the rumen leads to the production of intermediates, including trans-10, cis-12 conjugated linoleic acid (CLA), and when MAC-T cells are treated with this CLA isoform, it reduces cleavage of SREBP1 to its mature form, and reduces mRNA of $A C C 1, F A S N$, and SCD1 (Peterson et al., 2004). Dietinduced milk fat depression and trans-10, cis-12 CLA treatment also reduced SREBP1 mRNA in mammary tissue (Harvatine and Bauman, 2006). Similar to CLA treatment of mammary epithelial cells, use of siRNA in the present experiment reduced mature SREBP1 protein, de novo lipogenesis, and mRNA levels of $A C C 1$, $F A S N$, and $S C D 1$, but increased $A C C 1$ and FASN transcripts in response to LXR activation with reduced abundance of SREBP1, indicating a potential role for LXR in their regulation. Reductions in mammary tissue SREBP1 associated with diet-induced or CLA-induced milk fat depression could result, as proposed by Harvatine and Bauman (2006), from direct regulation of SREBP1 gene transcription by SREBP1 itself, as an SREBP1 response element is present in the promoter. Additionally, an LXR response element is present in the SREBP1 promoter (Lengi and Corl, 2010), and LXR may have a role in the transcriptional regulation of SREBP1 and lipogenic genes with promoters that include an LXR response element.

\section{ACKNOWLEDGMENTS}

This project was supported by National Research Initiative Competitive Grant no. 2009-35204-05358 from the US Department of Agriculture National Institute of Food and Agriculture (Washington, DC). The authors thank Andrea Lengi (Department of Dairy Science, Virginia Tech, Blacksburg) for assistance with primer validation.

\section{REFERENCES}

Baranowski, M. 2008. Biological role of liver X receptors. J. Physiol. Pharmacol. 59(Suppl. 7):31-55.

Barthel, A., K.-D. Krüger, R. Roth, and H.-G. Joost. 2002. Concentration-dependent stimulatory and inhibitory effect of troglitazone on 
insulin-induced fatty acid synthase expression and protein kinase B activity in 3T3-L1 adipocytes. Naunyn Schmiedebergs Arch. Pharmacol. 365:290-295. http://dx.doi.org/10.1007/s00210-0020529-y.

Chen, G., G. Liang, J. Ou, J. L. Goldstein, and M. S. Brown. 2004. Central role for liver $\mathrm{X}$ receptor in insulin-mediated activation of Srebp-1c transcription and stimulation of fatty acid synthesis in liver. Proc. Natl. Acad. Sci. USA 101:11245-11250. http:// dx.doi.org/10.1073/pnas.0404297101.

Darimont, C., O. Avanti, I. Zbinden, P. Leone-Vautravers, R. Mansourian, V. Giusti, and K. Macé. 2006. Liver X receptor preferentially activates de novo lipogenesis in human preadipocytes. Biochimie 88:309-318. http://dx.doi.org/10.1016/j.biochi.2005.08.010.

Ericsson, J., S. M. Jackson, J. B. Kim, B. M. Spiegelman, and P. A. Edwards. 1997. Identification of glycerol-3-phosphate acyltransferase as an adipocyte determination and differentiation factor 1- and sterol regulatory element-binding protein-responsive gene. J. Biol. Chem. 272:7298-7305. http://dx.doi.org/10.1074/jbc.272.11.7298.

Fiévet, C., and B. Staels. 2009. Liver X receptor modulators: Effects on lipid metabolism and potential use in the treatment of atherosclerosis. Biochem. Pharmacol. 77:1316-1327. http://dx.doi. $\operatorname{org} / 10.1016 /$ j.bcp.2008.11.026.

Foufelle, F., and P. Ferre. 2002. New perspectives in the regulation of hepatic glycolytic and lipogenic genes by insulin and glucose: A role for the transcription factor sterol regulatory element binding protein-1c. Biochem. J. 366:377-391.

Harvatine, K. J., and D. E. Bauman. 2006. SREBP1 and thyroid hormone responsive spot 14 (S14) are involved in the regulation of bovine mammary lipid synthesis during diet-induced milk fat depression and treatment with CLA. J. Nutr. 136:2468-2474.

Joseph, S. B., B. A. Laffitte, P. H. Patel, M. A. Watson, K. E. Matsukuma, R. Walczak, J. L. Collins, T. F. Osborne, and P. Tontonoz. 2002. Direct and indirect mechanisms for regulation of fatty acid synthase gene expression by liver $\mathrm{X}$ receptors. J. Biol. Chem. 277:11019-11025. http://dx.doi.org/10.1074/jbc.M111041200.

Kuriyama, H., G. Liang, L. J. Engelking, J. D. Horton, J. L. Goldstein, and M. S. Brown. 2005. Compensatory increase in fatty acid synthesis in adipose tissue of mice with conditional deficiency of SCAP in liver. Cell Metab. 1:41-51. http://dx.doi.org/10.1016/j. cmet.2004.11.004.

Lengi, A. J., and B. A. Corl. 2010. Short communication: Identification of the bovine sterol regulatory element binding protein-1c promoter and its activation by liver X receptor. J. Dairy Sci. 93:5831-5836. http://dx.doi.org/10.3168/jds.2010-3236.

Livak, K. J., and T. D. Schmittgen. 2001. Analysis of relative gene expression data using real-time quantitative $\mathrm{PCR}$ and the $2^{-\Delta \Delta \mathrm{CT}}$ method. Methods 25:402-408. http://dx.doi.org/10.1006/ meth.2001.1262.

Lopez, J. M., M. K. Bennett, H. B. Sanchez, J. M. Rosenfeld, and T. E. Osborne. 1996. Sterol regulation of acetyl coenzyme A carboxylase: A mechanism for coordinate control of cellular lipid. Proc. Natl. Acad. Sci. USA 93:1049-1053.

Ma, L., and B. Corl. 2012. Transcriptional regulation of lipid synthesis in bovine mammary epithelial cells by sterol regulatory element binding protein-1. J. Dairy Sci. 95:3743-3755.

Magaña, M. M., and T. F. Osborne. 1996. Two tandem binding sites for sterol regulatory element binding proteins are required for sterol regulation of fatty-acid synthase promoter. J. Biol. Chem. 271:32689-32694. http://dx.doi.org/10.1074/jbc.271.51.32689.

Mani, O., M. T. Sorensen, K. Sejrsen, R. M. Bruckmaier, and C. Albrecht. 2009. Differential expression and localization of lipid transporters in the bovine mammary gland during the pregnancy-lactation cycle. J. Dairy Sci. 92:3744-3756. http://dx.doi. org/10.3168/jds.2009-2063.

McFadden, J. W., and B. A. Corl. 2010. Activation of liver X receptor (LXR) enhances de novo fatty acid synthesis in bovine mam- mary epithelial cells. J. Dairy Sci. 93:4651-4658. http://dx.doi. org/10.3168/jds.2010-3202.

Molenaar, A., J. Mao, K. Oden, and H.-M. Seyfert. 2003. All three promoters of the acetyl-coenzyme A-carboxylase $\alpha$-encoding gene are expressed in mammary epithelial cells of ruminants. J. Histochem. Cytochem. 51:1073-1081. http://dx.doi. org $/ 10.1177 / 002215540305100811$.

Peet, D. J., S. D. Turley, W. Ma, B. A. Janowski, J.-M. A. Lobaccaro, R. E. Hammer, and D. J. Mangelsdorf. 1998. Cholesterol and bile acid metabolism are impaired in mice lacking the nuclear oxysterol receptor LXR $\alpha$. Cell 93:693-704. http://dx.doi.org/10.1016/ s0092-8674(00)81432-4

Peterson, D. G., E. A. Matitashvili, and D. E. Bauman. 2003. Diet-induced milk fat depression in dairy cows results in increased trans-10, cis-12 CLA in milk fat and coordinate suppression of mRNA abundance for mammary enzymes involved in milk fat synthesis. J. Nutr. 133:3098-3102.

Peterson, D. G., E. A. Matitashvili, and D. E. Bauman. 2004. The inhibitory effect of trans-10, cis-12 CLA on lipid synthesis in bovine mammary epithelial cells involves reduced proteolytic activation of the transcription factor SREBP-1. J. Nutr. 134:2523-2527.

Repa, J. J., G. Liang, J. Ou, Y. Bashmakov, J. M. Lobaccaro, I. Shimomura, B. Shan, M. S. Brown, J. L. Goldstein, and D. J. Mangelsdorf. 2000. Regulation of mouse sterol regulatory element-binding protein-1c gene (SREBP-1c) by oxysterol receptors, LXRalpha and LXRbeta. Genes Dev. 14:2819-2830. http://dx.doi.org/10.1101/ gad. 844900

Sabol, S. L., H. B. Brewer Jr., and S. Santamarina-Fojo. 2005. The human $A B C G 1$ gene: Identification of LXR response elements that modulate expression in macrophages and liver. J. Lipid Res. 46:2151-2167. http://dx.doi.org/10.1194/jlr.M500080-JLR200.

Schoonjans, K., L. Gelman, C. Haby, M. Briggs, and J. Auwerx. 2000. Induction of LPL gene expression by sterols is mediated by a sterol regulatory element and is independent of the presence of multiple E boxes. J. Mol. Biol. 304:323-334. http://dx.doi.org/10.1006/ jmbi.2000.4218.

Schultz, J. R., H. Tu, A. Luk, J. J. Repa, J. C. Medina, L. Li, S. Schwendner, S. Wang, M. Thoolen, D. J. Mangelsdorf, K. D. Lustig, and B. Shan. 2000. Role of LXRs in control of lipogenesis. Genes Dev. 14:2831-2838. http://dx.doi.org/10.1101/gad.850400.

Wang, P. H., Y. H. Ko, H. J. Chin, C. Hsu, S. T. Ding, and C. Y. Chen. 2009. The effect of feed restriction on expression of hepatic lipogenic genes in broiler chickens and the function of SREBP1. Comp. Biochem. Physiol. B Biochem. Mol. Biol. 153:327-331. http://dx.doi.org/10.1016/j.cbpb.2009.04.003.

Wang, X., R. Sato, M. S. Brown, X. Hua, and J. L. Goldstein. 1994. SREBP-1, a membrane-bound transcription factor released by sterol-regulated proteolysis. Cell 77:53-62. http://dx.doi. org/10.1016/0092-8674(94)90234-8.

Weiss, K., J. Mihály, G. Liebisch, T. Marosvölgyi, G. Schmitz, T. Decsi, and R. Rühl. 2011. Effect of synthetic ligands of PPAR $\alpha, \beta / \delta, \gamma, \mathrm{RAR}, \mathrm{RXR}$ and LXR on the fatty acid composition of phospholipids in mice. Lipids 46:1-8. http://dx.doi.org/10.1007/ s11745-011-3593-6.

Yin, H.-Q., M. Kim, J.-H. Kim, G. Kong, K.-S. Kang, H.-L. Kim, B.-I. Yoon, M.-O. Lee, and B.-H. Lee. 2007. Differential gene expression and lipid metabolism in fatty liver induced by acute ethanol treatment in mice. Toxicol. Appl. Pharmacol. 223:225-233. http:// dx.doi.org/10.1016/j.taap.2007.06.018.

Zhao, L. F., Y. Iwasaki, W. Zhe, M. Nishiyama, T. Taguchi, M. Tsugita, M. Kambayashi, K. Hashimoto, and Y. Terada. 2010. Hormonal regulation of acetyl-CoA carboxylase isoenzyme gene transcription. Endocr. J. 57:317-324. http://dx.doi.org/10.1507/ endocrj.K09E-298. 